\title{
Studying solid fuel ignition by $\mathrm{CO}_{2}$-laser
}

\author{
Alexander Korotkikh $^{1 *}$, Konstantin $V$. Slyusarskiy ${ }^{1}$, Ivan V. Sorokin ${ }^{1}$ \\ ${ }^{1}$ Tomsk Polytechnic University, Institute of Power Engineering, 634050, Tomsk, Russia
}

\begin{abstract}
The ignition data on Siberian bituminous coal and lignite by a continuous $\mathrm{CO}_{2}$-laser were presented in current work. Measurements were carried out at the heat flux density range of $90-150 \mathrm{~W} / \mathrm{cm}^{2}$ in air. Dependences of ignition delay time on heat flux density were obtained along with the surface temperatures at the moment of fuel sample ignition. Ignition delay time was found to be in the range 50-520 ms for lignite. For bituminous coal ignition the delay time values are larger 1.5-2 times. However, fuel surface temperature in the moment of ignition is the same for both fuels, i.e. $640-680^{\circ} \mathrm{C}$.
\end{abstract}

\section{Introduction}

Solid fuel is one of the most common among fossils which are used to produce energy worldwide [1]. However, coal-fired plants are the main source of pollution and greenhouse gas, like carbon, sulfur and nitrogen oxide, as well as solid particles (ash, slag) into environment [1]. Decreasing of the temperature in intense chemical reaction area during the solid fuel combustion is one of the methods for enhancing combustion efficiency and pollution mitigation (nitrogen oxide, in particular [1]). Lower temperature in fuel combustion area causes chemical reaction rate changing and, as a result, alters energy equipment characteristics. That's why studies on dependences and characteristics of gasification, ignition and combustion of widespread in Siberia coals are up-to-date.

Many studies on ignition of single coal particles [2] and coal dust in oxidizer flow [3] were presented in scientific literature recently. Majority are dedicated to conductive [4] or convective [5] heating. This creates the need for using criterial equations and heat-transfer coefficient to obtain heat flux. But in existing coal-fired boilers the main heat transfer mechanism in furnace is radiation [3]. There are significantly less articles on solid fuel ignition and combustion under conditions of radiant heating. In articles $[5,6]$ the data on ignition of coal powders with different disperse composition under conditions of radiant heat flux. In articles [7, 8] the results on radiant ignition of single coal particle are presented. In all mentioned above publications the impulse lasers with low exposure times, while in real conditions the emission is continuous.

The current study presents the experimental data on ignition by continuous radiant heat flux tests in air medium for two samples of energy coals with grade $\mathrm{T}$ and $2 \mathrm{~B}$

* Corresponding author: korotkikh@tpu.ru 


\section{Experimental section}

\subsection{Fuel samples}

The powders of T-grade bituminous coal and 2B-grade lignite of Kuznetsk and CanskAchinsk deposits were studied. Initial fuel was ground in a ball mill and sieved through a sieve with $80 \mu \mathrm{m}$ mesh size. Dispersed characteristics of investigated fuel samples were defined using laser-analyzer HELOS. The average diameters and characteristic sizes of coal powders are given in Table 1.

Table 1. Average diameter and characteristic size for studied fuel samples.

\begin{tabular}{|c|c|c|c|c|c|c|c|c|}
\hline \multirow{2}{*}{ Sample } & \multicolumn{4}{|c|}{ Average diameter, $\boldsymbol{\mu m}$} & \multicolumn{3}{c|}{ Characteristic size, $\boldsymbol{\mu m}$} \\
\cline { 2 - 9 } & $\boldsymbol{d}_{\mathbf{1 0}}$ & $\boldsymbol{d}_{\mathbf{2 0}}$ & $\boldsymbol{d}_{\mathbf{3 0}}$ & $\boldsymbol{d}_{\mathbf{3 2}}$ & $\boldsymbol{d}_{\mathbf{4 3}}$ & $\boldsymbol{x}_{\mathbf{1 0}}$ & $\boldsymbol{x}_{\mathbf{5 0}}$ & $\boldsymbol{x}_{\mathbf{9 0}}$ \\
\hline Coal T & $36.9 \pm 0.2$ & $45.4 \pm 0.2$ & $52.1 \pm 0.2$ & $69.2 \pm 0.1$ & $79.2 \pm 0.1$ & $6.45 \pm 0.1$ & $31.6 \pm 0.1$ & $75.3 \pm 0.2$ \\
\hline Coal 2B & $38.9 \pm 0.1$ & $47.3 \pm 0.1$ & $53.6 \pm 0.1$ & $69.7 \pm 0.1$ & $79.1 \pm 0.2$ & $6.80 \pm 0.2$ & $34.9 \pm 0.2$ & $77.5 \pm 0.1$ \\
\hline
\end{tabular}

The proximate and elemental analyses of two investigated samples are carried out according to ISO 17246:2010 methodic and using Euro EA 3000 analyzer. Analysis results are given in Table 2 .

Table 2. Proximate and ultimate analysis data for studied fuel samples.

\begin{tabular}{|c|c|c|c|c|c|c|c|c|c|}
\hline \multirow{2}{*}{ Sample } & \multicolumn{4}{|c|}{ Proximate analysis, wt. \% } & \multicolumn{4}{|c|}{ Ultimate analysis, wt. \% } \\
\cline { 2 - 10 } & M & A & V & FC & C & H & N & S & O \\
\hline Coal T & 3 & 21 & 20 & 66 & 68 & 4 & 3 & $<1$ & 4 \\
\hline Coal 2B & 7 & 16 & 32 & 45 & 50 & 4 & 2 & $<1$ & 28 \\
\hline
\end{tabular}

Here $\mathrm{M}, \mathrm{A}, \mathrm{V}$ and $\mathrm{FC}$ are the moisture, ash, volatile matter and fixed carbon content, respectively.

T-grade coal has higher fixed carbon and ash content while moisture and volatile matter content are higher for 2B-grade coal. Tested samples were pressed into tablets with $10 \mathrm{~mm}$ diameter under pressure $310 \mathrm{MPa}$. The density of tablets of T-grade coal was $1200 \mathrm{~kg} / \mathrm{m}^{3}$ and $1100 \mathrm{~kg} / \mathrm{m}^{3}$ for $2 \mathrm{~B}$-grade coal.

\subsection{Fuel ignition}

Study on solid fuel sample ignition was carried out using experimental setup for radiant heating based on continuous $\mathrm{CO}_{2}$-laser with $10.6 \mu \mathrm{m}$ wavelength and $200 \mathrm{~W}$ power. The front end of samples was visually controlled for pore, crack and cavity absence. Scheme of experimental setup is given in Fig.1.

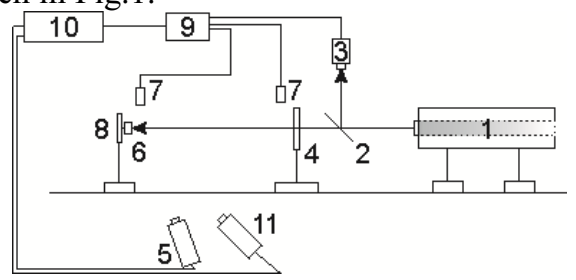

Fig. 1. Scheme of experimental setup based on $\mathrm{CO}_{2}$-laser: $1-\mathrm{CO}_{2}$-laser; 2 - semi-transparent; 3 thermoelectric sensor of radiation power; 4 - electromagnetic shutter; 5 - video camera; 6 - fuel sample; 7 - photodiode; 8 - holder; 9 - ADC; 10 - PC; 11 - thermal imaging camera.

Studied fuel sample (6) was attached to sample holder (8). After opening of shutter (4) the laser emission was directed to studied fuel sample (6). Signals from photodiode (7) and emission power measurer (3) were directed to personal computer (10) through ADC of signal L-card E-14-440 (9). Later they were processed via LGraph2 software. The fuel 
ignition delay time $t_{\text {ign }}$ was defined as a difference between signals from photodiodes (7): one registered the appearance of flame on the surface of sample, another one registered the opening of the shutter.

The surface temperature of samples during heating, gasification, ignition and combustion of fuel was registered with thermal imager Jade J $530 \mathrm{SB}$ with frequency $50 \mathrm{~Hz}$ in the temperature range of $260-1800{ }^{\circ} \mathrm{C}$. Thermo and video-imaging data as well as photodiode signal were synchronized by the signal of shutter opening. The radiant heat flux density was measured using Ophir FL400A thermoelectric sensor.

\section{Results and discussion}

\subsection{Sample ignition delay}

The dependencies of ignition delay time on radiant heat flux density for fuel samples are given in Fig. 2.

The presented data reveal that the ignition delay time for T-grade bituminous coal sample is $1.5-2.0$ times higher than for $2 \mathrm{~B}$-grade lignite sample. Increasing of the heat flux density from $90 \mathrm{~W} / \mathrm{cm}^{2}$ to $150 \mathrm{~W} / \mathrm{cm}^{2}$ decreases difference between the ignition times from 400 to $50 \mathrm{~ms}$ for both studied samples. It may be connected either with lower activation energy of the gasification process for lignite and to lower conductivity coefficient [9].

Experimental data was approximated using equation:

$$
t_{\text {ign }}=A \cdot q^{-B}
$$

where $t_{i g n}$ is the solid fuel ignition delay time, ms; $q$ is the heat flux density, $\mathrm{W} / \mathrm{cm}^{2} ; A, B$ are approximation constants.

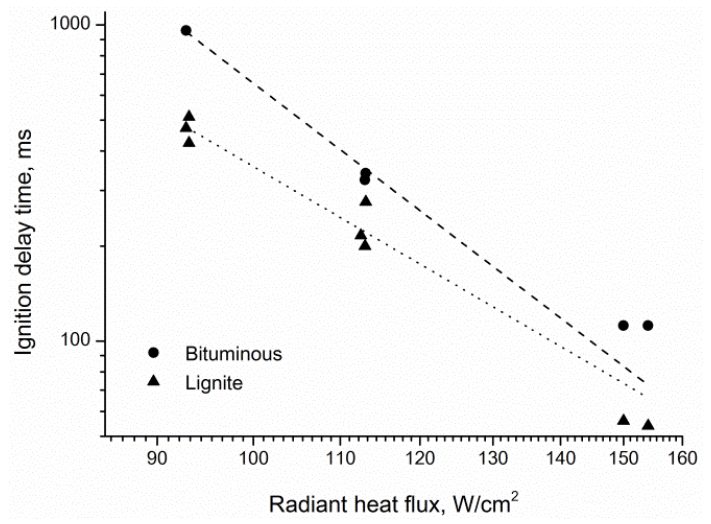

Fig. 2. The ignition delay time of solid fuel samples vs. radiant heat flux density.

Approximation constant values as well as determination coefficient $R^{2}$ are given in Table 3 .

Table 3. Approximation constants and determination coefficient values.

\begin{tabular}{|c|c|c|c|}
\hline Sample & $\boldsymbol{A}$ & $\boldsymbol{B}$ & $\boldsymbol{R}^{\mathbf{2}}$ \\
\hline Coal T & $9.61 \cdot 10^{12}$ & 5.8 & 0.99 \\
\hline Coal 2B & $2.20 \cdot 10^{10}$ & 3.9 & 0.96 \\
\hline
\end{tabular}




\subsection{Sample surface temperature}

The temperature distribution on the sample surface at the moment of flame appearance is presented in Fig. 3. The maximal and averaged surface temperatures of tested samples are presented in Table 4.

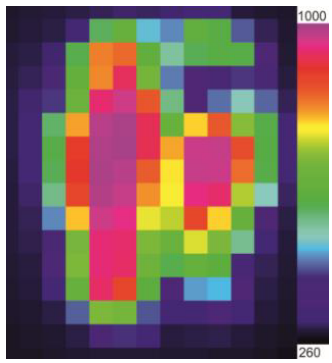

(a)

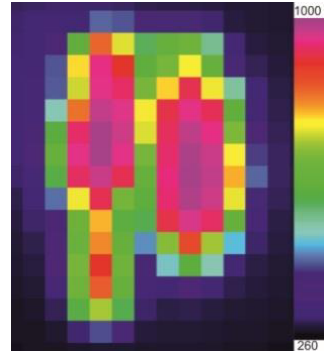

(b)

Fig. 3. Thermal imager data in the ignition moment at $q=113 \mathrm{~W} / \mathrm{cm}^{2}$ for fuel samples: (a) - T-grade coal; (b) - 2B-grade coal.

Table 4. Fuel sample surface temperatures at the ignition moment.

\begin{tabular}{|c|c|c|}
\hline Sample & Coal T & Coal 2B \\
\hline Maximal temperature, ${ }^{\circ} \mathrm{C}$ & 1038 & 1066 \\
\hline Average temperature, ${ }^{\circ} \mathrm{C}$ & 644 & 677 \\
\hline
\end{tabular}

The heating and ignition processes for tested solid fuels could be divided into two stages: intense heating with intense gasification and appearance of flame with transition into stable combustion. The obtained temperatures of sample surface in the moment of ignition of $\mathrm{T}$ grade and 2B-grade coals are close to each other.

\section{Conclusion}

The ignition process of $\mathrm{T}$-grade bituminous coal and 2B-grade lignite samples was studied using an experimental setup based on $\mathrm{CO}_{2}$-laser in air at normal conditions. The ignition delay time values for fuel samples were obtained in the radiant heat flux range of 90 $150 \mathrm{~W} / \mathrm{cm}^{2}$ and were in the range of $50-950 \mathrm{~ms}$. It was found that the ignition delay time for T-grade bituminous coal sample is 1.5-2.0 times higher than for 2B-grade lignite sample. The average surface temperature for fuel samples is equal to $640-680{ }^{\circ} \mathrm{C}$ during initiation by radiant heat flux $q=113 \mathrm{~W} / \mathrm{cm}^{2}$.

The reported study was supported by the Russian Scientific Foundation, Grant 16-19-10316.

\section{References}

1. Inventory of U.S. Greenhouse Gas Emissions and Sinks: 1990-2014. April 15, 2016

2. A.C. Sarroza, T.D. Bennet, C. Eastwick, H. Liu, Fuel Proc. Tech. 157, 1 (2017)

3. W. Cao, Q. Qin, W. Cao, Y. Lan, T. Chen, S. Xu, X. Cao, Powder Tech. 310, 17 (2017)

4. A.G. Korotkikh, K.V. Slyusarskiy, A.A. Ditts, Russ. J. Phys. Chem. B. 10, 576 (2016)

5. J.C. Chen, M. Taniguchi, K. Ito Fuel. 75, 323 (1995)

6. T.H. Dubaniewicz Jr., K.L. Cashdollar, G.M.J. Laser Appl. 15, 184 (2003)

7. M. Qu, M. Ishigaki, M. Tokuda, Fuel 75, 1155 (1996)

8. B.A. Wong, G.R. Gavalas, R.C. Flagan, Energy Fuels 9, 484 (1994)

9. V.G. Lisenco Fuel. Rational combustion, control and technological application (Teplotehnik, Moscow, 2003) [in Russian] 